\title{
Comparison Study on Hygric Performance of Bamboo Laminated Lumber and Bamboo Scrimber as Indoor Finishing in Hot-Humid Climate Region
}

\author{
Zujian HUANG ${ }^{1, a}$, and Yimin SUN ${ }^{2}$ \\ ${ }^{1}$ School of architecture, South China University of Technology, Guangzhou 510640, China \\ ${ }^{2}$ State Key Laboratory of Subtropical Building Science, Guangzhou 510640, China
}

\begin{abstract}
Bamboo laminated lumber (BSB) and bamboo scrimber (BFB) are two most typical products in bamboobased panel industry, which are widely used as building indoor finishing. The study aims to clarify the difference between BSB and BFB, in terms of the material property and the construction performance. Material tests including two items for basic properties and four for hygric properties were first carried out, and the results showed that under the influence of bamboo-based panel processing technology, BFB had significantly higher bulk density and lower open porosity, lower moisture storage as well as lower moisture transport properties than BSB. Based on the material parameters, exterior walls construction groups were set in the computer program WUFI Plus with a typical city in North America Hot-Humid climate region as external condition. The annual simulation of coupled heat and moisture process for the construction groups showed that BSB performed better in exhausting the moisture inside the construction, and strengthening the regulating effect on the indoor hygric environment. However, vapor barrier was suggested to be arranged in the upstream side of the moisture flow to avoid its hygric resistance disadvantage.
\end{abstract}

\section{Introduction}

Since the 1970s, wood processing technologies are taken as references for the investigations on industrial utilization of bamboo, afterwards various industrial bamboo products are successively developed [1]. Among the bamboo-based panel products, bamboo laminated lumber (abbreviated as BSB) retains the surface features of natural bamboo to the most extent, giving it a wellrecognized appearance, so that it is widely used as decorative panel for wall and flooring in building industry. In 2012, the bamboo flooring production in China was about 35 million $\mathrm{m}^{2}$, of which around 20 million $\mathrm{m}^{2}$ used BSB as the raw material, and the remaining 15 million $\mathrm{m}^{2}$ was mostly bamboo scrimber (abbreviated as BFB) [2].

BSB was first developed in China in the 1990s. Since then, various production methods have been developed, of which the mainstream one is to split the round bamboo culm into standard strip units with rectangular crosssection, and then recombine the units to form the final products. The manufacturing steps generally includes: raw bamboo - strip making - rough planning - strip selection - carbonization - drying carbonized strips - fine planning - adhesive coating - assembling (pressing strips to single layer sheet) - sanding the single layer sheet adhesive coating - pressing sheets to multiple layers board - sawing- sanding - dust absorption [1]. The research and development of BFB has matured in technology also in China in the 2000s. Microscopically, bamboo fibers are almost totally arranged in parallel, prompting that bamboo fiber-based products can play their inherent mechanical advantages. However, bamboo panel products composed of sufficiently separated fibers has not been successfully promoted due to their low added value and complicated manufacturing process [3]. For this reason, the constituent units are simplified as the loose bamboo fiber bundles, which are then recombined with high pressure in the forming process [4]. The manufacturing process generally includes: raw bamboo strip making - rough planning - strips splitting carbonization - carbonized strips drying - strips crushing adhesive using - strips pressing - glue activating in oven beams sawing - beams sanding [1]. Compared with BSB, the BFB changes the appearance and microstructure of a natural bamboo much more substantially.

Compared with timber, the bamboo-based panel products have both higher heat storage and heat transport properties, at the same time lower moisture storage and moisture transport properties [5]. By playing its heat storage advantages, the bamboo enclosed space units can surpass timber units of the same construction and space size in hot and temperate climate regions, in terms of energy-saving effect and the indoor thermal environment [6]. Worldwide bamboo forest distribution broadly overlaps these climate regions, making the local application of bamboo in building industry have dual benefits of utilizing the forest resource and the improving the local building performance. In previous study, the authors carried out factor impact analyses on the material

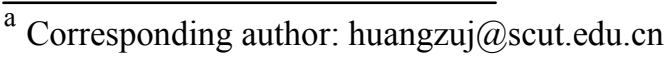


and construction parameters of bamboo layered walls, and gave climate responsive design optimization suggestions in terms of partition boards, thermal insulation infill and air layer arrangement in Hot-Humid climate regions [7].

As a construction element of the building envelope, the indoor finishing has important impact on the hygrothermal performance of the construction. It interchanges heat with the indoor air and performs heat radiation exchange with the indoor occupants. As a result, the surface thermal properties of the indoor finishing have effects on the indoor thermal environment and the thermal comfort of the occupants. BSB and BFB are two most typical products in bamboo-based panel industry, which are widely used as building indoor finishing. In hygric aspects, as hygroscopic materials, bamboo indoor finishing has also an important impact on the 'breathing effect' of the construction. In the Hot-Humid climate regions where the moisture flows mainly from the outdoor to the indoor, the indoor finishing affects the discharge rate of the moisture within the construction.

This study aimed to clarify the difference between $\mathrm{BSB}$ and $\mathrm{BFB}$, in terms of the material property and the construction performance. Material tests including two items for basic properties and four for hygric properties were first carried out. Based on this, the construction performance was simulated with a typical city in HotHumid climate region as external condition. The comparison study on material property of BSB and BFB, as well as their performance as an indoor finishing in exterior walls would provide reference for the bamboo processing and bamboo construction design in building industry.

\section{Material property comparison}

\subsection{Material sample}

The samples were provided by the Dasso Industrial Group Co. Ltd. in Hangzhou, China, who owned the core patents to produce these products. (Figure 1)
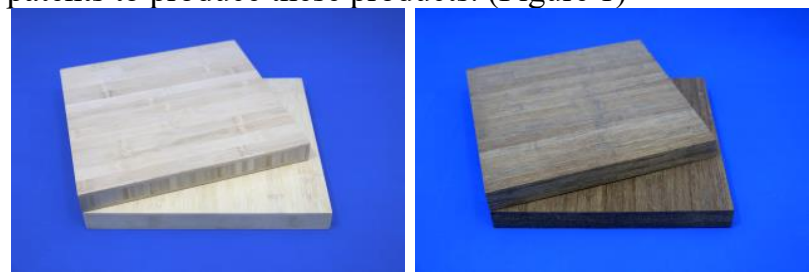

Figure 1. Photos of the material samples: left (BSB - bamboo laminated lumber) and right (BFB - bamboo scrimber).

\subsection{Test items}

The tests were divided into 2 groups, targeting the basic properties and the hygric properties, respectively. Test items included bulk density test and vacuum saturation test for the basic properties; sorption test for the moisture storage properties; capillary absorption test, water vapor transmission test and drying test for the moisture transport properties.

\subsection{Test methods}

The tests were performed according to the corresponding international standards. (Table 1, Figure 2)

Table 1. Methods of the material property tests.

\begin{tabular}{|c|c|c|}
\hline Category & Item & Operation method \\
\hline \multirow{3}{*}{ Basic properties } & Bulk density test & - \\
\cline { 2 - 3 } & Vacuum saturation test & $\begin{array}{c}\text { Refer to the American standard ASTM D7370-2009, and the European } \\
\text { standard DIN EN 1936-2007 [8,9] }\end{array}$ \\
\hline \multirow{4}{*}{ Hygric properties } & Sorption test & Refer to the international standard ISO 12571:2012 [10] \\
\cline { 2 - 3 } & Capillary absorption test & Refer to the international standard ISO 15148:2002(E) [11] \\
\cline { 2 - 3 } & Water vapor transmission test & $\begin{array}{c}\text { Refer to the international standard ISO 12572:2001(E) and the American } \\
\text { standard ASTM E 96/E 96M-2005 [12,13] }\end{array}$ \\
\cline { 2 - 3 } & Drying test & $\begin{array}{c}\text { Refer to the test method of Fraunhofer IBP (accredited according to DIN } \\
\text { EN ISO/IEC 17025) }\end{array}$ \\
\hline
\end{tabular}
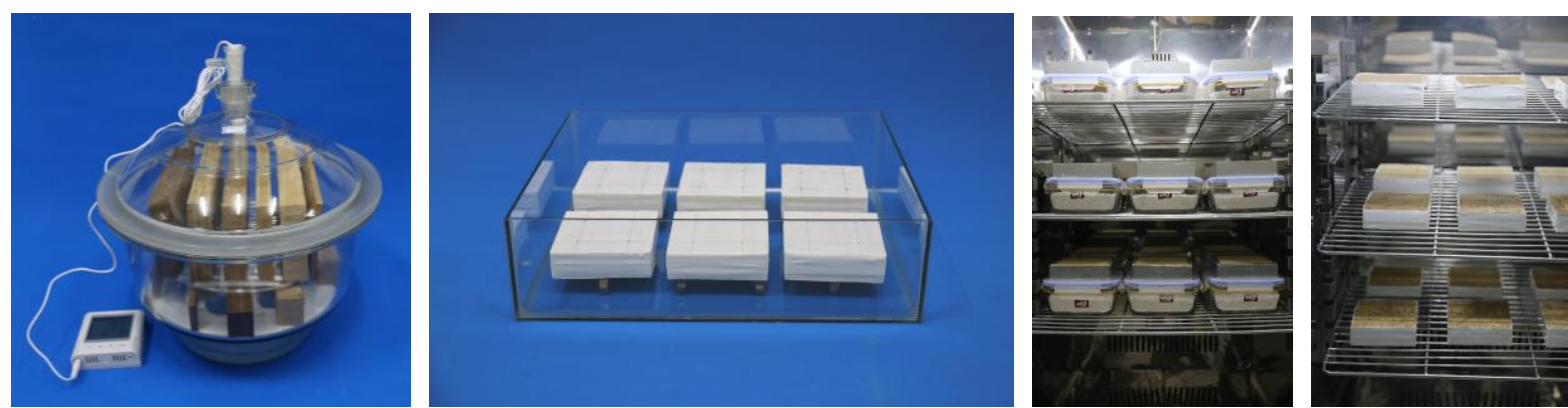

Figure 2. Photos of the equipment for hygric properties tests: from left to right: sorption test, capillary absorption test, water vapor transmission test and drying test. 


\subsection{Test results}

\subsubsection{Basic properties}

Compared with BSB, the bulk density of BFB was increased, while the open porosity reduced significantly. At BSB $100 \%$, the dry bulk density $\rho_{\mathrm{d}}$ and open porosity $\Phi$ of BFB was respectively $196.66 \%$ and $32.17 \%$. These were caused by the high pressure during the forming process, and the use of preservative and water repellent that partly blocked the pores of BFB.

\subsubsection{Hygric properties}

Compared with BSB, all the parameters that described the hygric properties of BFB showed different degrees of reduction. Taking the $20^{\circ} \mathrm{C}$ isothermal adsorption and desorption curve as indicator to characterize the moisture storage property, the test results ratio between BFB and BSB was in the range $37.89 \%-78.23 \%$. For the water absorption coefficient that described the liquid water transport property, this ratio was $11.09 \%$. Taking the water vapor transfer coefficient and the drying rate $(T=$ $23{ }^{\circ} \mathrm{C}, R H=50 \%$ ) as indicators to characterize the gaseous moisture storage property, at BSB $100 \%$, BFB were in the range $9.79 \%-38.35 \%$ and $15.89 \%-17.63 \%$, respectively. (Table 2)

Table 2. Material property test results

\begin{tabular}{|c|c|c|c|c|c|c|}
\hline Category & Target value & Notation & Condition & BSB & BFB & $\mathrm{BFB} / \mathrm{BSB}$ ratio \\
\hline \multirow{2}{*}{$\begin{array}{c}\text { Basic } \\
\text { properties }\end{array}$} & Dry bulk density & $\rho_{\mathrm{d}}\left[\mathrm{kg} / \mathrm{m}^{3}\right]$ & - & 563.81 & 1108.77 & $196.66 \%$ \\
\hline & Open porosity & $\Phi[\%]$ & - & 53.97 & 17.36 & $32.17 \%$ \\
\hline $\begin{array}{l}\text { Hygric } \\
\text { properties } \\
\text { - moisture } \\
\text { storage }\end{array}$ & $\begin{array}{c}20^{\circ} \mathrm{C} \text { isothermal } \\
\text { adsorption and } \\
\text { desorption curve, from } \\
R H=11.2 \% \text { to } \\
R H=96.3 \%\end{array}$ & $u[\%]$ & $\begin{array}{l}R H=11.2 \% \\
R H=24.4 \% \\
R H=33.4 \% \\
R H=43.5 \% \\
R H=55.0 \% \\
R H=59.7 \% \\
R H=77.2 \% \\
R H=85.4 \% \\
R H=96.3 \%\end{array}$ & $\begin{array}{c}1.61 \\
2.71 \\
3.81 \\
4.66 \\
5.97 \\
6.49 \\
9.51 \\
11.41 \\
17.87\end{array}$ & \begin{tabular}{c|}
0.61 \\
1.27 \\
1.83 \\
2.30 \\
2.72 \\
2.91 \\
4.85 \\
6.28 \\
13.98
\end{tabular} & $\begin{array}{l}37.89 \% \\
46.86 \% \\
48.03 \% \\
49.36 \% \\
45.56 \% \\
44.84 \% \\
51.00 \% \\
55.04 \% \\
78.23 \%\end{array}$ \\
\hline \multirow{3}{*}{$\begin{array}{c}\text { Hygric } \\
\text { properties } \\
\text { - moisture } \\
\text { transport }\end{array}$} & $\begin{array}{l}\text { Water absorption } \\
\text { coefficient }\end{array}$ & $A_{\text {cap }}\left[\mathrm{E}^{-04} \mathrm{~kg} /\left(\mathrm{m}^{2} \mathrm{~s}^{0.5}\right)\right]$ & - & 78.74 & 8.73 & $11.09 \%$ \\
\hline & $\begin{array}{c}\text { Water vapor transfer } \\
\text { coefficient, from } \\
R H=20.0 \% \text { to } \\
R H=93.0 \%\end{array}$ & $\delta\left[\mathrm{E}^{-13} \mathrm{~kg} /(\mathrm{m} \mathrm{s} \mathrm{Pa})\right]$ & $\begin{array}{l}R H=20.0 \% \\
R H=25.0 \% \\
R H=35.0 \% \\
R H=45.0 \% \\
R H=50.0 \% \\
R H=73.0 \% \\
R H=83.0 \% \\
R H=93.0 \%\end{array}$ & $\begin{array}{c}21.66 \\
22.72 \\
24.83 \\
26.94 \\
27.99 \\
47.98 \\
188.16 \\
-\end{array}$ & $\begin{array}{c}2.12 \\
2.50 \\
3.25 \\
3.99 \\
4.37 \\
18.40 \\
26.47 \\
40.97\end{array}$ & $\begin{array}{c}9.79 \% \\
11.00 \% \\
13.09 \% \\
14.81 \% \\
15.61 \% \\
38.35 \% \\
14.07 \% \\
-\end{array}$ \\
\hline & $\begin{array}{c}\text { Drying rate }\left(T=23^{\circ} \mathrm{C},\right. \\
R H=50 \%), \text { from } \\
u=12 \% \text { to } u=6 \%\end{array}$ & $U\left[\mathrm{E}^{-07} \mathrm{~kg} /\left(\mathrm{m}^{2} \mathrm{~s}\right)\right]$ & $\begin{array}{c}u 12 \%-u 11 \% \\
u 11 \%-u 10 \% \\
u 10 \%-u 9 \% \\
u 9 \%-u 8 \% \\
u 8 \%-u 7 \% \\
u 7 \%-u 6 \%\end{array}$ & $\begin{array}{l}74.22 \\
66.64 \\
58.87 \\
60.01 \\
52.75 \\
48.72\end{array}$ & $\begin{array}{l}12.58 \\
11.46 \\
10.38 \\
9.71 \\
8.98 \\
7.74\end{array}$ & $\begin{array}{l}16.95 \% \\
17.20 \% \\
17.63 \% \\
16.18 \% \\
17.02 \% \\
15.89 \%\end{array}$ \\
\hline
\end{tabular}

\section{Construction performance comparison}

\subsection{Simulation model design}

Construction groups for comparison were set in the coupled heat and moisture process simulation program WUFI Plus, which was developed by the Fraunhofer IBP [14]. The models were composed of external condition, internal condition, boundary condition and HVAC condition. Annual hourly simulation was carried out, involving the exterior walls hygric performance (HVAC on), the HVAC demand (HVAC on), and the indoor hygric environment. The operation period was set from 2015-01-01 to 2017-01-01, in which the whole hourly data of the second year were collected for analysis. (Table 3) 
For the boundary condition, the exterior walls (each 9 $\mathrm{m}^{2}$ ) were the study objects, while the floor and ceiling were set as partitions between the two rooms of the same interior conditions to avoid heat and moisture flow. Two commonly used construction types were considered, including the L-type (outdoor board + infill layer + indoor finishing) and the M-type (outdoor masonry + infill layer + indoor finishing) groups. (Table 4)

Table 3. Simulation model design

\begin{tabular}{|c|c|c|c|}
\hline External conditions & Internal conditions & Boundary conditions & HVAC conditions \\
\hline $\begin{array}{c}\text { Meteorological parameters of } \\
\text { Miami, a typical city from the } \\
\text { North American 1A (very hot \& } \\
\text { humid) climate region, including } \\
\text { both cool year and warm year }\end{array}$ & $\begin{array}{c}(3 \mathrm{~m})^{3} \text { units, with standard } \\
\text { office indoor heat and moisture } \\
\text { load: } \\
\text { convective heat: } 33.3 \mathrm{~W} \\
\text { radiant heat: } 25.2 \mathrm{~W} \\
\text { moisture: } 17.55 \mathrm{~g} / \mathrm{h} \\
\mathrm{CO}_{2}: 20.79 \mathrm{~g} / \mathrm{h} \\
\text { human activity: } 1.2 \mathrm{met}\end{array}$ & See Table 4 & $\begin{array}{c}\text { HVAC off: export the indoor } \\
\text { hygric environment } \\
\text { HVAC on: maintain the indoor air } \\
\text { as } T_{\mathrm{i}}=20-26^{\circ} \mathrm{C}, R H_{\mathrm{i}}=40 \%-60 \% \\
\text { with ideal HVAC devices, export } \\
\text { the exterior walls hygric } \\
\text { performance and the HVAC } \\
\text { demand of the enclosed space }\end{array}$ \\
\hline
\end{tabular}

Table 4. Boundary conditions design - exterior walls construction design

\begin{tabular}{|c|c|c|c|}
\hline Group & Exterior layer & Indoor finishing & Infill layer \\
\hline \multirow{2}{*}{$\mathrm{L}$} & $\mathrm{BFB}(18 \mathrm{~mm})$ & $\mathrm{BFB}(12 \mathrm{~mm})$ & $\mathrm{BF}(30 \mathrm{~mm})$ \\
& $\mathrm{BSB}(12 \mathrm{~mm})$ & $\mathrm{BF}+\mathrm{PE}(30 \mathrm{~mm}+0.2 \mathrm{~mm})$ \\
\hline \multirow{2}{*}{$\mathrm{LB}(120 \mathrm{~mm})$} & $\mathrm{BFB}(12 \mathrm{~mm})$ & $\mathrm{BF}(30 \mathrm{~mm})$ \\
& & $\mathrm{BSB}(12 \mathrm{~mm})$ & $\mathrm{BF}+\mathrm{PE}(30 \mathrm{~mm}+0.2 \mathrm{~mm})$ \\
\hline
\end{tabular}

Abbreviation: BSB - Bamboo laminated lumber; BFB - Bamboo scrimber; BF - Natural bamboo fiber infill; LB - Lime silica brick; PE - PE foil

\subsection{Simulation results}

\subsubsection{Exterior walls hygric performance}

In HVAC on conditions, the moisture flowed mainly from outdoor to indoor through the exterior walls, therefore the difference among BSB and BFB as indoor finishing mainly depended on their capacity to release the moisture within the construction. For L-type construction, since the amount of moisture that penetrated into the construction was relatively small, the difference between $\mathrm{BSB}$ and BFB model groups was insignificant, that the annual mean moisture content of the BF layer $w-B F_{\text {mean }}$ ratio between $\mathrm{BSB}$ and $\mathrm{BFB}$ groups was in the range $96.41 \%-96.67 \%$. In contrast, the difference was highlighted in M-type groups, in which the ratio was lowered to $56.24 \%-80.63 \%$, showing the obvious advantages of BSB. For the annual moisture flow through the exterior walls $M_{\text {flow }}$, the simulation result of BSB groups was $137.83 \%-212.00 \%$ compared with that of the BFB groups, resulting from the smaller moisture transport resistance of the BSB.

\subsubsection{HVAC demand}

The difference between BSB and BFB as indoor finishing was only highlighted in the M-type construction. Due to the smaller moisture transport resistance of the construction, the annual moisture flow through the exterior walls $M_{\text {flow }}$ was larger in the model groups with
BSB as interior board, resulting in larger humidification $\&$ dehumidification demand than that of the BFB groups. The $\mathrm{H}$ value ratio between $\mathrm{BSB}$ and $\mathrm{BFB}$ groups was in the range $110.98 \%-155.40 \%$. However, this was reversed when arranging $0.2 \mathrm{~mm}$ PE foil at the outer side of the BF layer, that the ratio was lowered to $98.55 \%-99.17 \%$. This indicated that the arrangement of moisture barrier layer on the upstream side of the moisture flow could help to reduce the humidification \& dehumidification demand by playing effectively the stronger moisture adjustment capacity of BSB.

\subsubsection{Indoor hygric environment}

In HVAC off conditions, compared with BFB, simulation results showed that $\mathrm{BSB}$ with higher moisture transport properties was conducive to exert its regulation of the indoor air moisture, so that lowered the amplitude of the indoor relative humidity. For the L-type construction group, the simulation results ratio of $R H_{\text {i.amp }}$ between $\mathrm{BSB}$ and $\mathrm{BFB}$ as indoor finishing was in the range $76.50 \%-78.90 \%$. This was increased slightly to $83.00 \%$ $92.83 \%$ for the M-type group. (Table 5, Figure 3) 
Table 5. Construction performance simulation results

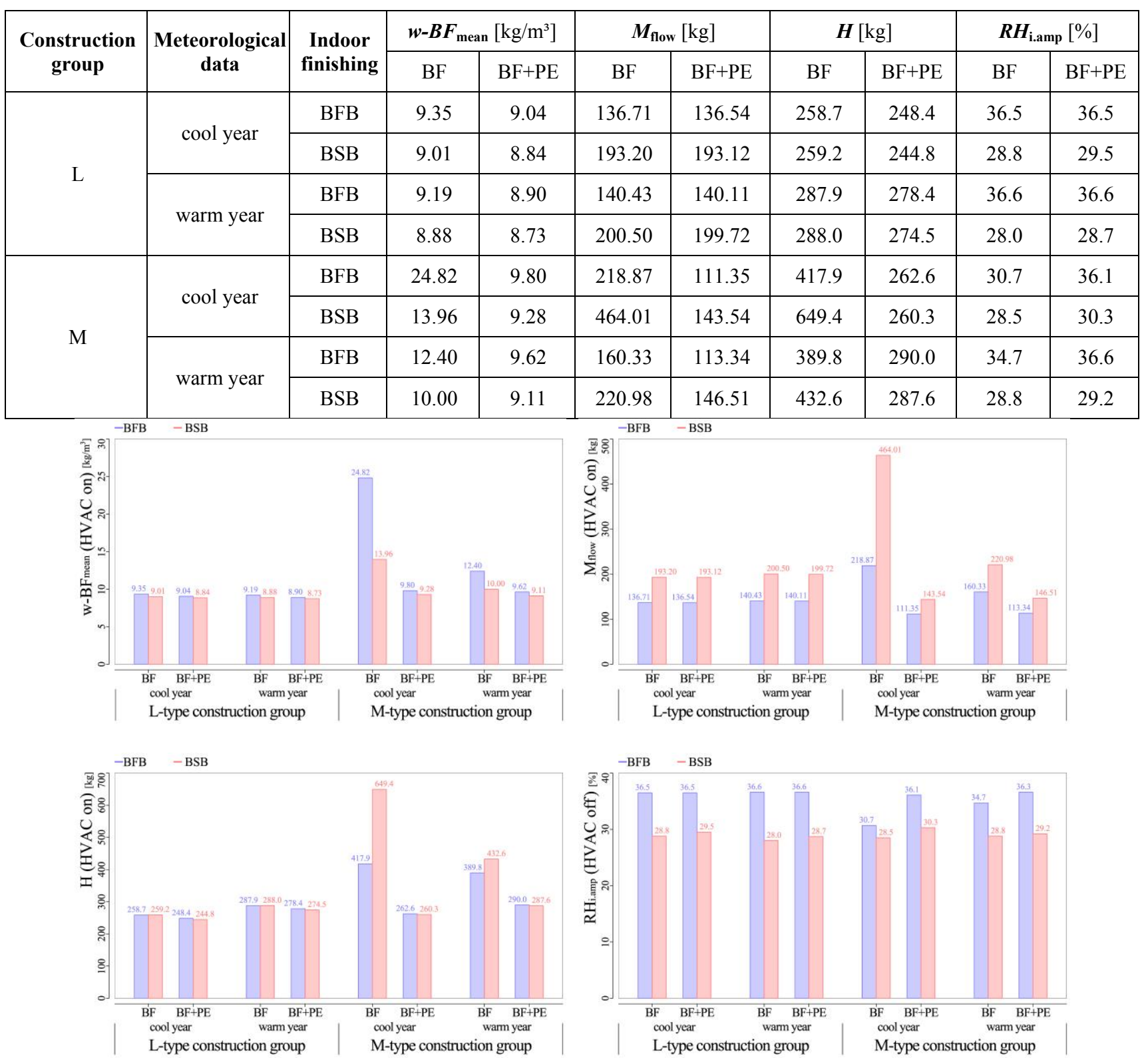

Figure 3. Construction performance simulation results

\section{Conclusion}

Bamboo laminated lumber and bamboo scrimber are both popular indoor finishing materials in building industry, which are produced through different bamboo-based panel processes. In this study, the material property test results showed that BFB has significantly higher bulk density and lower open porosity, lower moisture storage as well as lower moisture transport properties than BSB. The simulation in Hot-Humid climate regions showed that the larger moisture storage capacity and faster moisture transport rate enabled it to perform better than $\mathrm{BFB}$, by accelerating the exhaust of moisture inside the construction, and strengthening the regulating effect on the indoor hygric environment. However, vapor barrier was suggested to be arranged in the upstream side of the moisture flow to avoid its hygric resistance disadvantage.
As a hygroscopic material used in building envelope, hygrothermal properties and hygrothermal performance on material and construction levels should both be investigated. It was insufficient for this study that only hygric aspects had been discussed. Further study in terms of the thermal properties and thermal performance should be carried out for the materials and their corresponding construction.

\section{Acknowledgments}

The research project is funded by: the National Natural Science Foundation of China (51908219), the Fundamental Research Funds for the Central Universities (D2181640), the China Postdoctoral Science Foundation (2018M640782), and the Guangzhou Science and Technology Program key projects (201707020041). 


\section{References}

1. Zhang Q, Jiang S and Tang Y. Industrial Utilization on Bamboo (Beijing, China: International Network for Bamboo and Rattan) chapter 2 26-35 (2002)

2. Huang Z. Application of Bamboo in Building Envelope (Cham, Switzerland: Springer International Publishing) chapter 1 18-19 (2019)

3. Li H, Zhu Y, Yang Z, et al. Review on the Studies of Bamboo Microstructure and Bamboo Fiber Application in China. Journal of Forestry Engineering 3 1-5 (in Chinese) (2013)

4. $\mathrm{Wu} \mathrm{B}, \mathrm{Yu} \mathrm{Y}$ and Qi J, et al. Effects of bamboo bundles treated with fine fluffing and carbonized treatment on the properties of bamboo scrimber Journal of Nanjing Forestry University (Natural Sciences Edition) 6 115-120 (in Chinese) (2014)

5. Huang Z, Sun Y and Musso F. Experimental study on bamboo hygrothermal properties and the impact of bamboo-based panel process Construction and Building Materials 155 1112-25 (2017)

6. Huang Z, Sun Y and Musso F. Assessment of bamboo application in building envelope by comparison with reference timber Construction and Building Materials 156 844-60 (2017)

7. Huang Z, Sun Y and Musso F. Hygrothermal performance optimization on bamboo building envelope in Hot-Humid climate region Construction and Building Materials 202 223-45 (2019)

8. ASTM D7370-2009: Standard Test Method for Determination of Relative Density and Absorption of Fine, Coarse and Blended Aggregate Using Combined Vacuum Saturation and Rapid Submersion ( West Conshohocken: ASTM International) 1-8 (2009)

9. DIN EN 1936-2007: Natural stone test method Determination of real density and apparent density, and of total and open porosity (Berlin: German Institute for Standardisation) 1-10 (2007)

10. ISO 12571:2012: Hygrothermal performance of building materials and products - Determination of hygroscopic sorption properties (Geneva: International Organization for Standardization) 1-8 (2012)

11. ISO 15148:2002(E): Hygrothermal performance of building materials and products - Determination of water absorption coefficient by partial immersion (Geneva: International Organization for Standardization) 1-9 (2002)

12. ISO 12572:2001(E): Hygrothermal performance of building materials and products - Determination of water vapour transmission properties (Geneva: International Organization for Standardization) 1-14 (2001)

13. ASTM E 96/E 96M-2005: Standard Test Methods for Water Vapor Transmission of Materials (West Conshohocken: ASTM International) 1-8 (2005)

14. Künzel H M. Simultaneous heat and moisture transport in building components (Suttgart: Fraunhofer IRB) 6-46 (1995) 